\title{
Determinants of access to primary health care for the elderly in the province of Essaouira
}

\author{
Hicham Mejdouli ${ }^{1}$, Abdellatif Baali ${ }^{1}$, Hakima Amor ${ }^{1}$, Nadia Ouzennou ${ }^{2}$ \\ ${ }^{1}$ Laboratory of Pharmacology, Neurobiology, Anthropobiology, Environment and Behaviour, Cadi Ayyad University, \\ Faculty of Sciences Semlalia, Marrakech. \\ ${ }^{2}$ Higher Institute of Nursing and Health Techniques, Marrakech
}

\begin{abstract}
Morocco is experiencing demographic and epidemiological changes marked by an increase in the proportion of elderly people accompanied by a growing prevalence of chronic diseases and disabilities, thus leading to an increase in the demand for health care. the Moroccan health system therefore faces the challenge of meeting the specific needs of older populations in terms of access to and use of health care services. To achieve this, the World Health Organisation (WHO) recommends a community-based approach, based on primary health care facilities (PHCFs), to the provision of services for older people.

This is a descriptive, cross-sectional study based on a quantitative approach. The survey was carried out via a questionnaire intended for a sample of 739 people aged 60 years and over attending the ESSPs in the province of Essaouira between January and February of the year 2020.

Our study has allowed us to understand the determinants related to the use of PHC by the elderly in the province of Essaouira. These determinants concern the characteristics of the elderly as well as the organisational and institutional aspects of the care offer. The bivariate analysis of the results showed a statistically significant association between the use of PHC by the elderly and the area of residence, gender, level of education, distance travelled to health facilities, quality of reception, and availability of medicines.

Policymakers are called upon to consider the determinants of the use of PHC in order to better address the health needs of older people, and also to respond to WHO guidance in this area.
\end{abstract}

Key words: Determinants, access to care, elderly people, Morocco. 


\section{Introduction}

Population ageing is one of the most striking demographic developments in modern societies worldwide [1]. The number of people aged 60 and over is increasing in most countries of the world, and it is expected to continue to increase in the coming decades [2].

Morocco is not immune to this trend. The sixth National Population and Family Health Survey (ENPSF) of 2018 indicates that people aged 60 and over in Morocco represent $11.1 \%$ of the total population, compared to $8 \%$ in 2004 and $8.9 \%$ in 2014 [3]. According to the projections of the Haut-Commissariat au Plan (HCP), the rate of growth of the elderly will be very rapid in the future. Thus, the share of this population group would be $15.4 \%$ in 2030 [4].

However, the increase in life expectancy is accompanied by a deterioration in health status and the emergence of new age-related diseases that older people have to face [5]. Thus, the ageing of the population leads to an increase in health care expenditure, as the use of health care services and the consumption of medicines, ,by the elderly is higher than in other age groups [6]. In this sense, the last ENPSF revealed that $64.4 \%$ of people aged 60 and over are affected by at least one chronic condition, and that only $56.6 \%$ of these patients follow a regular treatment [3]. The increase in the proportion of elderly people in the population is therefore accompanied by an increase in the need for geriatric care [6].

In this context, marked by the rapid ageing of the world's population, the World Health Organisation (WHO) recommends that countries prepare their health and social systems to promote the health of older people and prevent age-related diseases by adopting a community-based approach based on primary health care [7]. "Primary health care is a whole-of-society approach to health that aims to ensure the highest attainable standard of health and well-being and its equitable distribution by prioritising people's needs at the earliest possible stage along the continuum of care from health promotion and disease prevention to treatment, rehabilitation and palliation, and by remaining as close as possible to people's daily environment. » [8]

In this sense, the Moroccan health authorities are committed to improving the care offer for the elderly and to responding to their specific needs. The Ministry of Health has paid particular attention to this category of the population through the implementation of measures targeted in the Health Plan 2025 [9].

However, several factors influence access to primary health care in the elderly. Studies that have identified these factors are multiple $[10,11]$. In addition to the socio-demographic and economic characteristics of the elderly and their state of health, the response of the health system to the needs of this category of population (proximity, quality of reception, waiting time, availability of medicines, etc.) constitute the main determinants of access to care according to these studies.

In the province of Essaouira, the location of our study, the HCP data indicate that the socio-demographic and economic characteristics of the population are unfavourable compared to the national level. The vulnerability rate is $22.2 \%$ compared to $12.5 \%$ at the national level; the poverty rate is $9.1 \%$ compared to $4.8 \%$ at the national level and the illiteracy rate is $48.9 \%$ compared to $32.2 \%$ at the national level [12]. However, no survey has studied the effects of these characteristics on the access of the elderly to health care services in general and primary health care in particular in this province.

The objective of this study, therefore, is to explore the current state of access to primary health care among the elderly and the factors that influence this access in the province of Essaouira.

\section{Subject and methods}

This is a descriptive study, based on a quantitative approach, which was carried out in the health centres of the province of Essaouira(Marrakech-Safi Region, Morocco) which has a total population of 442,739 inhabitants, $75 \%$ of whom are rural. Public health care, in this province, is provided mainly by health centres. In total, the province has 68 health centres and only one public hospital.

The study was carried out over a 12-month period. Data collection took place between November 2020 and January 2021.

The target population, for the study, people aged 60 years and over who visited the study sites during the survey period. Elderly people with mental retardation or psychotic disorders were excluded from the study. Nonprobability accidental sampling was adopted for the recruitment of the survey participants. A total of 739 elderly people were interviewed.

The survey used a questionnaire that was designed following a literature review to construct three items: socio-demographic and economic characteristics, health status, and access to health services.

The data collected was entered and processed by SPSS version 20.0 (IBM Statistical Package for the Social Sciences), which enabled us to describe the study population statistically and to carry out statistical correlation tests.

All required ethical considerations were respected, including anonymity, confidentiality of responses and the right to participate or not in the survey.

\section{Results}

\section{Socio-demographic characteristics of the elderly subjects studied}

The total sample size was 739 people aged 60 and over attending health centres during the data collection 
period.

The survey revealed that $75 \%$ of the elderly were from rural areas. The sex ratio was 0.8 . The mean age was 67.1 (standard deviation $=6.6$ years) with extremes ranging from 60 to 101 years. The male sex had an average age of 67.6 , while the female sex had an average of 66.7 years. The 60-69 age group was the most represented $(70 \%)$.

Table 1 presents the main socio-demographic and economic characteristics of the subjects aged 60 and over participating in the study.

Table 1: Socio-demographic and economic characteristics of the elderly subjects studied.

\begin{tabular}{|c|c|c|}
\hline Variables & Workforce & $\%$ \\
\hline \multicolumn{3}{|l|}{ Gender } \\
\hline Male & 337 & 46 \\
\hline Female & 402 & 54 \\
\hline \multicolumn{3}{|l|}{ Age groups } \\
\hline 60-69 years old & 519 & 70 \\
\hline $70-79$ years old & 178 & 24 \\
\hline $80-89$ years old & 28 & 4 \\
\hline 90 years and over & 14 & 2 \\
\hline \multicolumn{3}{|l|}{ Place of residence } \\
\hline Urban & 185 & 25 \\
\hline Rural & 554 & 75 \\
\hline \multicolumn{3}{|l|}{ Level of education } \\
\hline No & 614 & 83 \\
\hline Primary & 76 & 10 \\
\hline Secondary or higher & 49 & 7 \\
\hline \multicolumn{3}{|l|}{ Marital status } \\
\hline Single & 52 & 7 \\
\hline Married & 480 & 65 \\
\hline Divorced & 44 & 6 \\
\hline Widow(er) & 163 & 22 \\
\hline \multicolumn{3}{|l|}{ Cohabitation } \\
\hline Living Alone & 222 & 30 \\
\hline Living as a family & 517 & 70 \\
\hline \multicolumn{3}{|l|}{ Occupation } \\
\hline Retired & 93 & 23.3 \\
\hline Employee & 43 & 10.8 \\
\hline Independent & 49 & 12.3 \\
\hline No profession & 215 & 53.8 \\
\hline \multicolumn{3}{|l|}{ Source of fixed income } \\
\hline Yes & 344 & 46.5 \\
\hline No & 395 & 53.5 \\
\hline \multicolumn{3}{|c|}{ Financial aid (child, relative, etc.) } \\
\hline Yes & 406 & 55 \\
\hline No & 333 & 45 \\
\hline
\end{tabular}


On the other hand, Figure 1 shows that about $30 \%$ of the elderly interviewed had no medical coverage at the time of the survey. The majority $(57 \%)$ were covered by the

\section{Régime d'Assistance Médicale aux Economiques \\ Démunis (RAMED) and $30 \%$ had no coverage.}

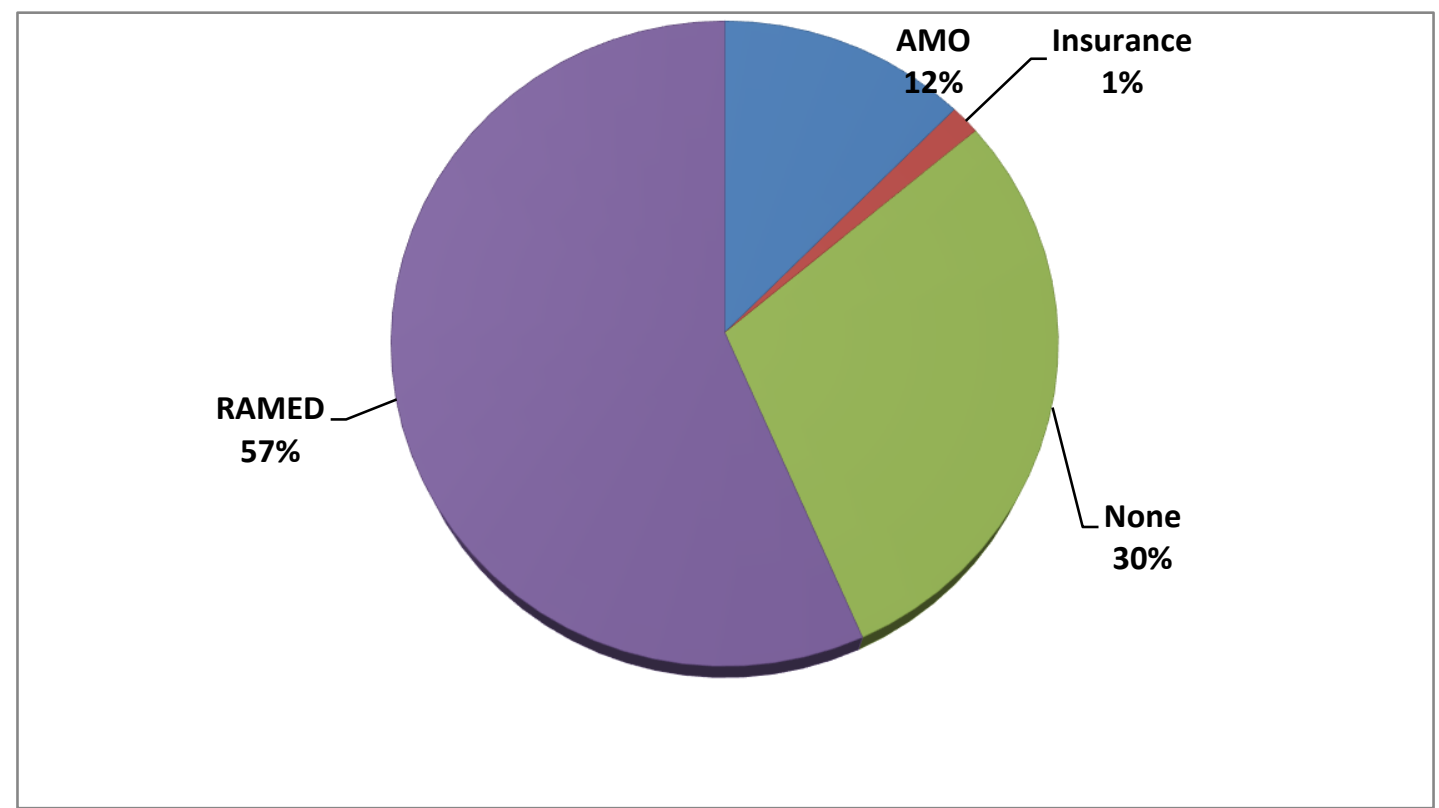

Figure 1: Distribution of older people by type of medical coverage

\section{Health status of study participants}

Regarding the perception of the elderly, about their health status at the time of the study, more than half of the participants in the study $(60 \%)$ perceived themselves to be in average health, $25 \%$ in poor health and $15 \%$ in good health.

The proportion of older people who considered their

Table 2: Frequency of chronic diseases in the elderly

\section{Chronicillness}

\section{Diabetes}

High blood pressure

\section{Cardiovascular diseases}

\section{Asthma}

Arthritis

Adenoma of the prostate

Other

On the other hand, $60 \%$ of the elderly declared having one or more difficulties limiting their daily activity. The most frequent disabilities among the elderly health to be poor was higher among women (59\%) than among men (41\%).

Regarding morbidity, Table 2 shows that $59 \%$ of the elderly interviewed reported having at least one chronic disease, with $30 \%$ reporting two or more chronic diseases.

Workforce $\quad \%$

$\begin{array}{ll}224 & 30 \\ 123 & 17\end{array}$

70

30

81

11

11

1

30 are related to visual impairment $(n=312)$, hearing impairment $(n=132)$ and mobility $(n=115)$, with some elderly having more than one difficulty (Table 3 ). 
Table 3: Distribution of types of activity-limiting difficulties in older people

\begin{tabular}{lcc}
\hline Difficulties limiting their daily activity & Workforce & \% \\
\hline Visual impairments & 312 & 42 \\
Hearing impairments & 132 & 18 \\
Motor impairments & 115 & 16 \\
Memory problems & 92 & 9 \\
Speech difficulties & 66 & 92 \\
\hline
\end{tabular}

\section{Access to care for older people}

The majority of respondents $(66 \%)$ live more than $3 \mathrm{~km}$ from the nearest health centre. To get from their home to the health facility, only $34 \%$ of the elderly use a means of transport, while $66 \%$ travel on foot.

The results of the study showed that more than half
$(56 \%)$ of the elderly people questioned were dissatisfied with the services offered in the care facilities, while $44 \%$ were satisfied. Figure 2 shows that the main reasons for dissatisfaction are lack of medication, non-medical care facilities and inadequate reception.
Non-dispensability of medicines

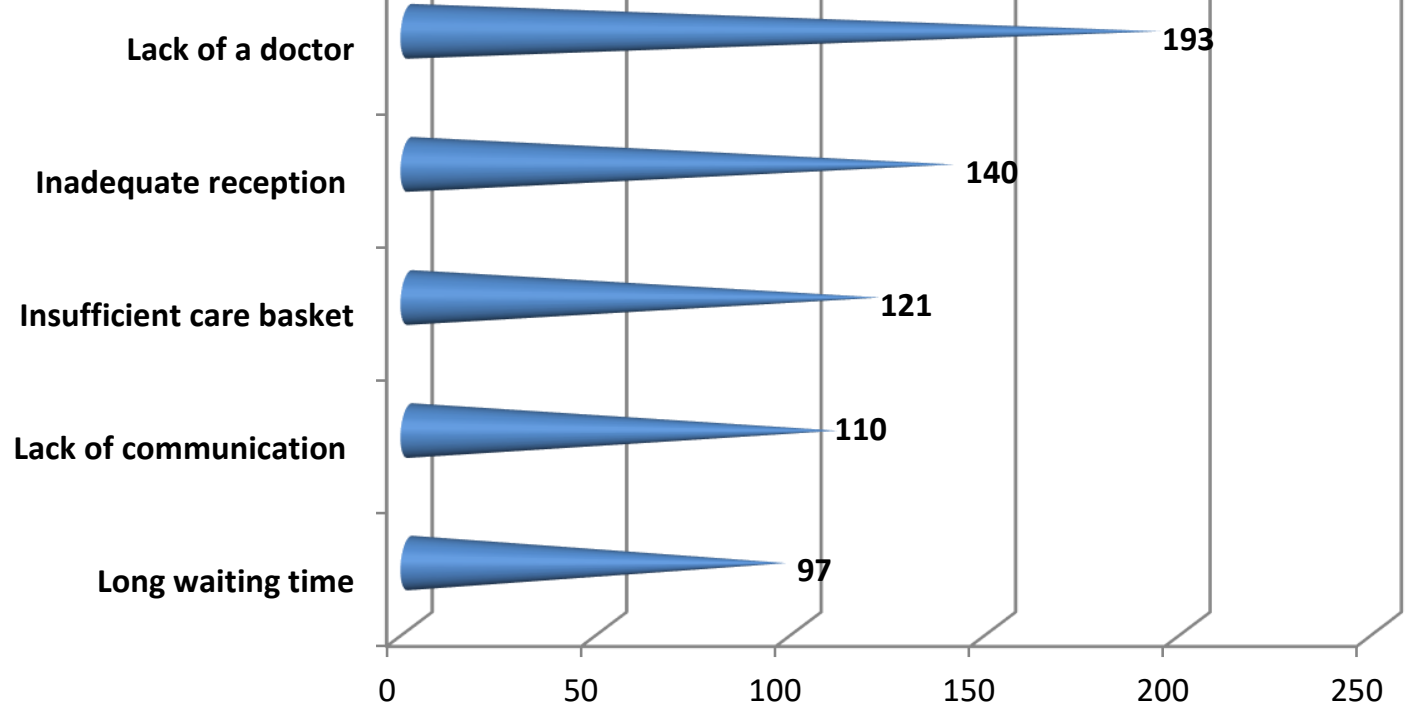

Figure 2: Reasons for dissatisfaction with health care services in health centres, as reported by the elderly surveyed

However, multivariate analysis using the binary logistic regression model (Table 4) shows that older people's use of health centres is strongly associated with a range of characteristics.

In order to identify possible associations, the respondents were stratified into two groups while referring to the recommendations of good medical practice for the follow-up of chronic diseases (at least one visit per quarter): the first group $(n=347)$ concerns patients who responded that they had visited the health centre less than 4 times in the 12 months preceding the study (i.e. less than one visit per quarter) and the second group $(n=392)$ concerns patients who had visited the health centre 4 times or more during the same period (i.e. one visit per quarter or more).

The analysis of the different determinants showed that there were statistically significant associations between the number of visits of older people to PHC and certain characteristics, namely: gender, age, residence, morbidity, distance to the health facility, quality of care, and availability of medicines.

However, no significant association was not found between access to health centres and the other characteristics studied. 
Table 4: Study of the association between the use of public health care facilities and the socio-demographic and health characteristics of the elderly

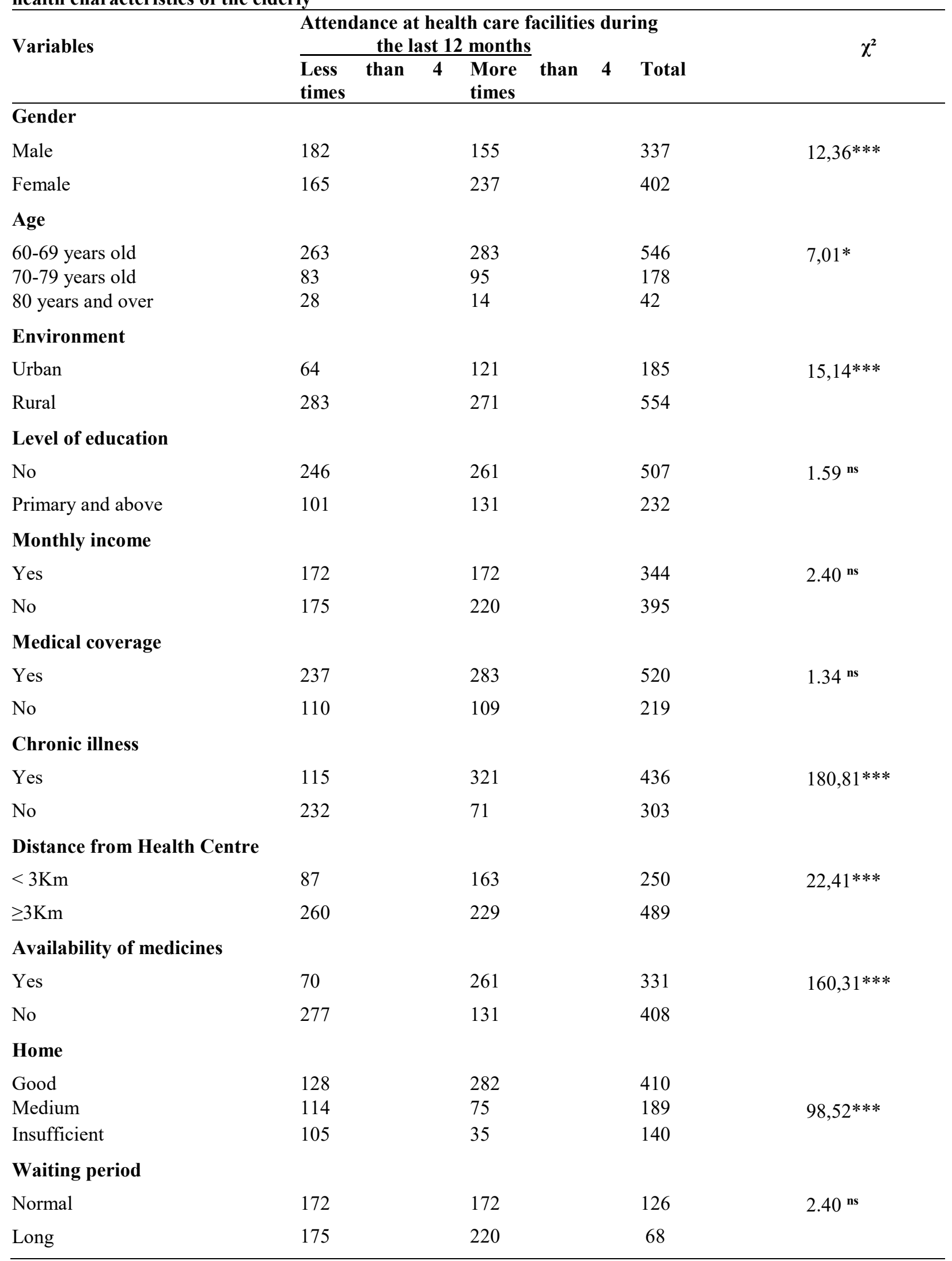

$* \mathbf{p}<0.05 ; * * \mathbf{p}<0.01, * * * \mathbf{p}<0.001 ;$ ns: not significant 


\section{Discussion}

The objective of this study was to explore the status of and factors influencing access to primary health care among the elderly in the province of Essaouira. The main results revealed that there are disparities in access to primary health care for the elderly and that this access is influenced by several factors.

Indeed, socio-demographic characteristics of the elderly such as advanced age, female gender, rural residence (isolation and remoteness) and low level of education are factors that negatively impact on the use of PHC by the elderly. These findings corroborate those of many international studies on health service utilization that have highlighted the role of sociodemographic profile in determining the use of PHC $[14,15,16]$.

Regarding morbidity, our survey revealed that $59 \%$ of elderly people attending health centres during the survey period reported having at least one chronic disease compared to $64.4 \%$ at the national level; diabetes and hypertension were the chronic diseases most reported by the people surveyed with proportions of $30 \%$ and $17 \%$ respectively. These results are in line with those of the 2018 ENPSF [2]. In the same sense, recent studies in several countries show that the presence of chronic diseases is among the main factors for the use of primary health care services by older people $[10,16]$.

As for medical coverage, the results of our study revealed that $57 \%$ of the elderly who use ESSPs are covered by RAMED (Scheme for the poor and vulnerable categories of the Moroccan population) and $30 \%$ do not have medical coverage involving the financing of care costs for this category. However, it has been reported in previous studies that the lack of medical coverage is a limiting factor in the use of health services by the elderly [14].

On the other hand, the results of our study showed that the majority $(56 \%)$ of the elderly people questioned stated that they were dissatisfied with the services offered at health facilities. These results are in line with those of other studies that have found a link between the use of health centres and the availability of medicines and technical facilities [17, 18, 19].

Caregiver-client relationship and communication have been reported in several studies as factors affecting regular use of health facilities by the population, especially the elderly $[20,21]$. Our results have also shown that the lack of a good reception is an obstacle that has a disabling effect on the use of PHC by the elderly. It should also be noted that other studies have indicated the lack of quality of reception and humanisation of care in PHC as factors likely to influence the use of health facilities by the elderly [22, 23].

\section{Conclusion}

The proportion of people aged 60 and over in Morocco is increasing more rapidly than any other age group. The vulnerability and specific needs of this population group call for special attention from health system managers to improve access to care for the elderly.

Indeed, our study has identified the main factors influencing the use of primary health care services by the elderly. These factors relate to the sociodemographic characteristics of the elderly as well as to the organisational and institutional aspects of the care offered, such as the distance travelled to reach health facilities, the quality of reception, the technical facilities offered and the availability of medicines.

In order to improve and better respond to the health needs of the elderly and to be in line with the WHO guidelines in this field, we propose to the decision-makers to create a specific care pathway for the elderly and to introduce a service approach, based on quality and proximity, which will serve to reconcile the elderly with the care system.

Finally, we hope that the results of this work will contribute to improving access to care for older people, and will serve as a basis for further research that will take into account the limitations of this survey, namely the openness of older people's access to hospital care and the views of health professionals on the use of care services by older people.

\section{Bibliographic references}

[1] Nations Unies, Les personnes âgées,2019 .https://www.un.org/fr/sections/issues-depth/ageing [Consulté le 12/01/2020]

[2] Ministère de la santé, Enquête Nationale sur la Population et la Santé Familiale, Maroc, 2018.

[3] Nations Unies, Perspectives démographiques mondiales : révisions 2017,Division de la population du Département des affaires économiques et sociales, 2017

[4] Observatoire National du Développement Humain, Situation des personnes âgées au Maroc, 2017.

[5] Haute Ecole De Santé Vaud, Vieillissement de la population, soins de transition et fin de vie, 2019

[6] David E Bloom et al., Macroeconomic implications of population ageing and selected policy responses, vol. 385, no. 9968, pp. 649-657, 2016.

[7] Organisation mondiale de la Santé Vieillissement et santé, 2018.https://www.who.int/fr/news-room/factsheets/detail/ageing-and-health [Consulté le 22/01/2020]]

[8] OMS et UNICEF, A vision for primary health care in the 21st century: towards universal health coverage and the Sustainable Development Goals, 2018

[9] Ministère de la santé, Plan Santé 2025, Maroc, 2018. 
[10] E. Madyaningrum, Y. Chuang, and K. Chuang, Factors associated with the use of outpatient services among the elderly in Indonesia, pp. 1-9, 2018.

[11] T. M. Farid et al., "Perspective of Elderly on Age-Friendliness of Services Provided in Primary Healthcare Centers of Dubai Health Authority: Focus Groups Discussions,” pp. 132-144, 2018.

[12] Haut-Commissariat au Plan, recensement général de la population et de l'habitat, Maroc, 2014

[13] B. Fret et al., Access to care of frail community-dwelling older adults in Belgium: a qualitative study,

[14] S. O. Wandera, B. Kwagala, and J. Ntozi, Determinants of access to healthcare by older persons in Uganda: A cross-sectional study," Int. J. Equity Health, vol. 14, no. 1, pp. 1-10, 2015.

[15] M. Jiang, G. Yang, L. Fang, J. Wan, Y. Yang, and Y. W. Id, "Factors associated with healthcare utilization among community-dwelling elderly in Shanghai , China," pp. 1-22, 2018.

[16] A. Paula, S. Coelho, B. Pereira, N. Iii, S. Manjourany, and S. Duro, Socioeconomic determinants of access to health services among older adults : a systematic review, pp. 1-15, 2017.

[17] J. Almeida, M. Lubenow, A. Jaquelyne, R. Barrêto, J. D. A. Nogueira, and A. O. Silva, Access for the Elderly to Primary Health Care Services: an Integrative Review,pp. 1-13, 2016

[18] M. Yunus, N. Hazilah, A. Manaf, and A. Omar, Determinants of Healthcare Utilisation among the Elderly in Malaysia, vol. 9, no. 3, pp. 115-140, 2017.

[19] A. Nipun, S. V. Prakash, S. A. Kumar, and I. Danish, "Original Research Article Healthcare services utilization by geriatric population in rural area of District Bareilly, India," vol. 4, no. 5, pp. 720-727, 2015.

[20] G. Van Rooy, P. Mufune, and E. Amadhila, "Experiences and Perceptions of Barriers to Health Services for Elderly in Rural Namibia: A Qualitative Study," 2015.

[21] P. Boeckxstaens, C. De, H. Kaduskiewicz, and S. I. Uk, "International exchange Primary care and care for older persons : Position Paper of the European Forum for Primary Care," pp. 369-389, 2011.

[22] G. Frumence, T. Nyamhanga, and A. Anaeli, Facilitators and barriers to health care access among the elderly in Tanzania: A health system perspective from managers and service providers., J. Aging Res. Healthc., vol. 2, pp. 20-31, 2017.

[23] A. Alkhawaldeh, M. B. Holm, J. Qaddumi, W. Petro, M. Jaghbir, and O. Al Omari, "A CrossSectional Study to Examine Factors Associated with Primary Health Care Service Utilization among Older Adults in the Irbid Governorate of Jordan," vol. 2014, pp. 1-8, 2014. 